Check for updates

Cite this: RSC Adv., 2017, 7, 20172

Received 25th February 2017

Accepted 31st March 2017

DOI: $10.1039 / c 7 r a 02338 c$

rsc.li/rsc-advances

\section{Novel AIE columnar liquid crystals: the influence of the number of diphenylacrylonitrile groups on the mesomorphic and fluorescence properties $\uparrow$}

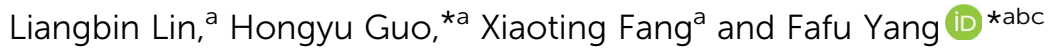

\begin{abstract}
The novel triphenylene derivatives with one, two or three diphenylacrylonitrile groups on the side chain were prepared in yields of $75-83 \%$. The influence of the number of diphenylacrylonitrile groups on the mesophase and fluorescence properties were investigated. The triphenylene derivatives with one or two diphenylacrylonitrile groups exhibited not only the ordered hexagonal columnar mesophase but also good AIE fluorescence properties in both solution and solid state.
\end{abstract}

Columnar discotic liquid crystals, possessing the unique cores with $\pi-\pi$ stacking structures, have attracted much commercial and academic research interest over the years. ${ }^{1}$ They were high ordered columnar mesophases with fast charge carrier mobility, exhibiting application prospects in various fields such as organic field-effect transistors, organic light-emitting diodes, organic photovoltaic cells, gas sensors, and so on. ${ }^{2-5}$ Recently, columnar luminescent liquid crystals have been paid considerable attention due to their effective combination of an intrinsic luminescence capability, the supramolecular organization and self-healing characteristic within a mesophase. ${ }^{6,7}$ For example, by using perylene or Bodipy as aromatic conjugated core, ${ }^{8-20}$ the luminescent liquid crystals could be constructed conveniently. However, although most of reported luminescent liquid crystals showed high fluorescence in solution, they could not emit fluorescence effectively in solid-state due to the aggregation caused quenching (ACQ) effect. Thus, various molecular designs were applied to avoid the ACQ effect,,$^{21,22}$ but often enhanced the expense of ordered molecular packing, making the synthesis of light-emitting liquid crystalline material a difficult task.

Recently, Tang's group discovered the aggregation-induced emission (AIE) effect, which implied the aggregation could enhance the light emission..$^{23-25}$ Obviously, introduction of AIEactive dye into liquid crystal is a good strategy to solve the above problem. Thus, some liquid crystalline molecules with AIE effect were designed and synthesized by grafting the long alkyl chains on AIE molecules such as diphenylacrylonitrile and

${ }^{a}$ College of Chemistry and Chemical Engineering, Fujian Normal University, Fuzhou 350007, P. R. China. E-mail: yangfafu@fjnu.edu.cn

${ }^{b}$ Fujian Key Laboratory of Polymer Materials, Fuzhou 350007, P. R. China

${ }^{c}$ Fujian Provincial Key Laboratory of Advanced Materials Oriented Chemical Engineering, Fuzhou 350007, P. R. China

$\dagger$ Electronic supplementary information (ESI) available: Experimental details, supporting figures and table. See DOI: $10.1039 / \mathrm{c} 7 \mathrm{ra02338 \textrm {c }}$ tetraphenylethene. ${ }^{26-37}$ However, most reported AIE liquid crystals were smectic or nematic mesophases, and only one columnar AIE liquid crystal was obtained by mixing tetraphenylethene-triphenylene oligomer with 2,4,7-trinitrofluorenone. ${ }^{37}$ These AIE liquid crystals were difficult to form columnar mesophase although they usually possessed highly symmetric structures containing a rigid aromatic core with several soft side-chains. The reason might be attributed to that the conjugated aromatic rings of AIE molecules are not the complete coplanar structures, which are against effective $\pi-\pi$ packing in column. Based on this speculation, it could be deduced that the columnar AIE liquid crystal could be prepared by using normal discotic coplanar aromatic structure as core which was favourable for columnar mesophase, and controlling the numbers of AIE groups on side chain to avoid the destruction of columnar mesophase. But no paper concerned on this study up to now. In order to confirm this speculation, in this paper, three novel triphenylene liquid crystals with multiple diphenylacrylonitrile groups were designed and synthesized. Moreover, the influences of the numbers of diphenylacrylonitrile groups on mesomorphic and fluorescence properties were investigated. The experimental results confirmed the above speculation that the mesomorphic and fluorescence properties were influenced greatly by the numbers of AIE groups on side chains. The triphenylene liquid crystals with one or two diphenylacrylonitrile groups exhibited not only good AIEluminescence property but also ordered hexagonal columnar mesophase.

It is well known that the monohydroxytriphenylene was a convenient platform to construct various triphenylene liquid crystals with good columnar mesophase.$^{38-47}$ On the other hand, the excellent AIE-fluorescence property of diphenylacrylonitrile had been reported extensively. ${ }^{23-25}$ Thus, by using monohydroxytriphenylene and diphenylacrylonitrile as building blocks, the triphenylene derivatives with one, two or three 
diphenylacrylonitrile groups were designed to investigate the influences of the numbers of diphenylacrylonitrile groups on mesomorphic and fluorescence properties. The synthetic routes were illustrated in Scheme 1. According to the reported methods ${ }^{46}$ By reacting monohydroxytriphenylene 1 with ethyl chloroacetate and then hydrazinolysis with $\mathrm{NH}_{2} \mathrm{NH}_{2}$, the triphenylene hydrazide derivative 3 was prepared in total yield of $68 \%$ after purification. On the other hand, by condensating $4-$ hydroxyphenylacetonitrile with benzaldehyde in $\mathrm{NaOH} / \mathrm{EtOH}$ system, the diphenylacrylonitrile derivative 4 with hydroxyl group was synthesized in yield of $80 \%$. Further refluxing compound 4 with excess 1-bromo-3-chloropropane in $\mathrm{K}_{2} \mathrm{CO}_{3} /$ MeCN system, the diphenylacrylonitrile derivative $\mathbf{5}$ containing terminal $\mathrm{Cl}$ group was obtained in yield of $72 \%$ after recrystallization. Subsequently, by reacting compound 5 with 4-hydroxybenzaldehyde, 3,4-dihydroxybenzaldehyde or 2,3,4trihydroxybenzaldehyde in $\mathrm{K}_{2} \mathrm{CO}_{3} / \mathrm{MeCN}$ system, the corresponding mono-, di- and tri-diphenylacrylonitrile derivatives $\mathbf{6}$, 7 and 8 bearing aldehyde group were collected in yields of $85 \%$, $71 \%$ and $66 \%$, respectively. Finally, the target triphenylene derivatives 9, 10 and 11 with one, two or three diphenylacrylonitrile groups were prepared in yield of $75-83 \%$ by Schiff-based condensation of compounds $\mathbf{6}, 7$ and $\mathbf{8}$ with triphenylene hydrazide derivative 3 under the catalysis of several drops of glacial acetic acid.

The structures of target compounds $\mathbf{9 ,} \mathbf{1 0}$ and $\mathbf{1 1}$ were confirmed by ${ }^{1} \mathrm{H}$ NMR, ${ }^{13} \mathrm{C}$ NMR, MALDI-TOF-MS and HR-MS spectral analysis. The corresponding molecular ion peaks $\left(\mathrm{M}^{+}\right.$, $\mathrm{MH}^{+}$or $\mathrm{MNa}^{+}$, see ESI $\dagger$ ) were observed in their mass spectrometry spectra, suggesting the accomplishment of Schiffbased condensation. In their ${ }^{1} \mathrm{H}$ NMR spectra, all protonic signals were in accordance with the corresponding structures
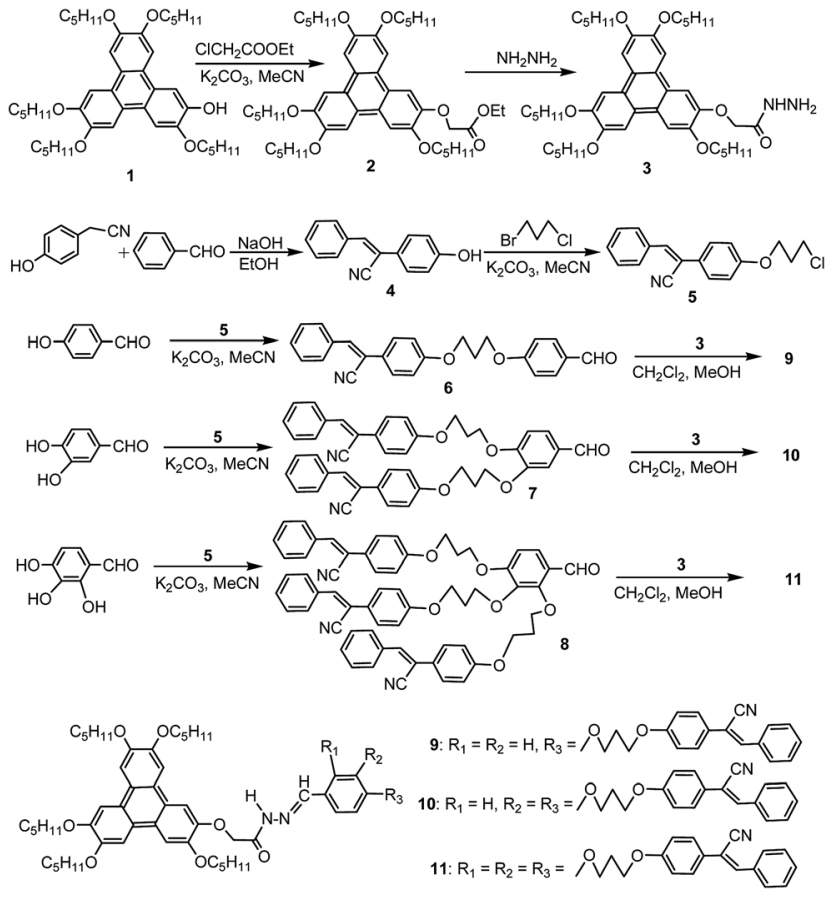

Scheme 1 Synthetic routes of target compounds 9, 10 and 11 . (see ESI†ं). Although compounds $\mathbf{1 0}$ and $\mathbf{1 1}$ possessed the overlapped protonic signals for the ArH due to their very similar structures of multiple diphenylacrylonitrile units, the clear singlets for $\mathrm{NH}, \mathrm{HC}-\mathrm{Ar}$ and $\mathrm{OCH}_{2} \mathrm{CO}$, and the accurate integrals for corresponding protons supported their structures in Scheme 1 . The ${ }^{13} \mathrm{C}$ NMR spectra also agreed with their structures. For example, only one peak at about $164 \mathrm{ppm}$ implied one kind of $\mathrm{C}=\mathrm{O}$ group in compounds $\mathbf{9 , 1 0}$ and $\mathbf{1 1}$.

As triphenylene derivatives with one, two or three diphenylacrylonitrile groups $\mathbf{9 ,} \mathbf{1 0}$ and $\mathbf{1 1}$ had been prepared, the influences of the numbers of diphenylacrylonitrile groups on mesomorphic properties were further studied by differential scanning calorimeter (DSC), polarizing optical microscopy (POM) and X-ray diffraction (XRD). Their DSC curves of samples 9, 10 and 11 for second heating and cooling were shown in Fig. 1. The data of phase transition temperatures and corresponding enthalpy changes were summarized in Table 1 . It can be seen that the triphenylene derivative 9 with one diphenylacrylonitrile group exhibited two phase transition peaks upon cooling at $123.1{ }^{\circ} \mathrm{C}$ and $39.7{ }^{\circ} \mathrm{C}$, and on second heating at $43.7^{\circ} \mathrm{C}$ and $129.2^{\circ} \mathrm{C}$, respectively. The triphenylene derivative 10 with two diphenylacrylonitrile groups also showed the similar transition at $113.2{ }^{\circ} \mathrm{C}$ and $40.2{ }^{\circ} \mathrm{C}$ on cooling, and at $51.7^{\circ} \mathrm{C}$ and $117.2{ }^{\circ} \mathrm{C}$ upon second heating. However, the triphenylene derivative $\mathbf{1 1}$ with three diphenylacrylonitrile groups only possessed one broad peak on cooling and seconding heating at $57.2{ }^{\circ} \mathrm{C}$ and $59.8{ }^{\circ} \mathrm{C}$, respectively. These data might suggest that samples $\mathbf{9}$ and $\mathbf{1 0}$ with one or two diphenylacrylonitrile groups had the transition of crystalline phasemesophase-isotropic phase during heating and cooling, but compound 11 with three diphenylacrylonitrile groups showed only crystalline phase-isotropic phase transition without mesophase. Moreover, these results implied that, as speculated, the rigid and un-coplanar AIE structure of diphenylacrylonitrile group made great influence on the liquid crystalline property. The more numbers of diphenylacrylonitrile groups resulted in the strong destruction to columnar mesophase. The temperature scope of mesophase for sample $\mathbf{9}$ with one diphenylacrylonitrile group was $85.5{ }^{\circ} \mathrm{C}$, which was higher than that of

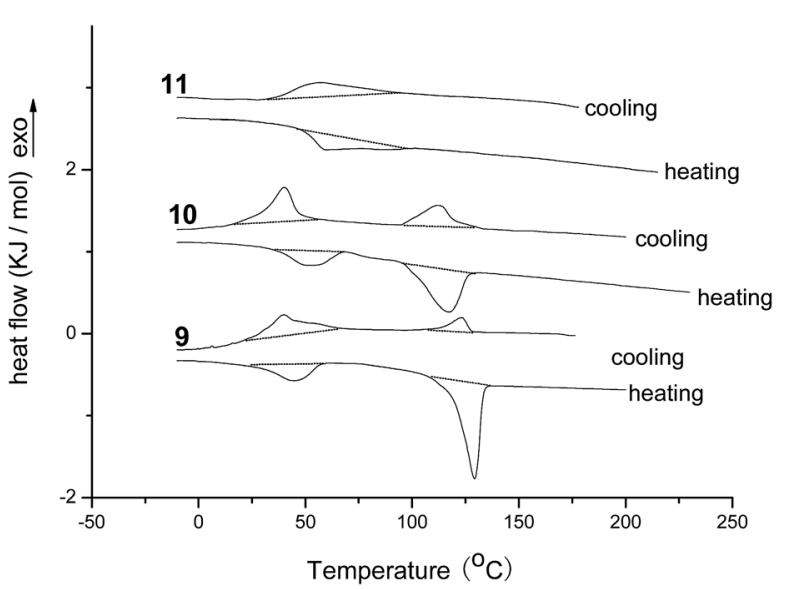

Fig. 1 The DSC traces of compounds 9, 10 and 11 upon second heating and cooling (scan rate $10{ }^{\circ} \mathrm{C} \mathrm{min}^{-1}$ ). 
Table 1 Transition temperatures $\left({ }^{\circ} \mathrm{C}\right)$ and enthalpy changes $\left(\mathrm{kJ} \mathrm{mol}^{-1}\right)$ of samples 9,10 and 11

\begin{tabular}{llll}
\hline Compd. & Phase transition $^{a}$ & Heating scan $T(\Delta H)$ & Cooling scan $T(\Delta H)$ \\
\hline $\mathbf{9}$ & Cr-Col & $43.7(10.1)$ & $39.7(13.2)$ \\
& Col-Iso & $129.2(21.5)$ & $123.1(5.6)$ \\
$\mathbf{1 0}$ & Cr-Col & $51.7(11.3)$ & $40.2(15.6)$ \\
& LC-Iso & $117.2(18.6)$ & $113.2(12.8)$ \\
$\mathbf{1 1}$ & Cr-Iso & $59.8(22.4)$ & $57.2(24.7)$ \\
${ }^{a} \mathrm{Cr}=$ crystalline, Col = columnar mesophase, Iso = isotropic.
\end{tabular}

sample 10 with two diphenylacrylonitrile group $\left(65.5^{\circ} \mathrm{C}\right)$. Three diphenylacrylonitrile groups on triphenylene derivative $\mathbf{1 1}$ destroyed the mesomorphic properties completely. These results suggested that, based on the strong columnar-induced packing capability of triphenylene unit, the triphenylene derivatives with one or two diphenylacrylonitrile groups still possessed the columnar mesophase.

Under the POM observation, sample 11 exhibited the Cr-Iso phase transition upon heating and cooling, and no mesophase was observed. However, compounds $\mathbf{9}$ and $\mathbf{1 0}$ showed the $\mathrm{Cr}-$ Col and Col-Iso phase transition at the approximate temperatures of DSC curves. As slowly cooling from isotropic phase, the liquid crystalline textures formed gradually. The corresponding textures for samples $\mathbf{9}$ and $\mathbf{1 0}$ at $70{ }^{\circ} \mathrm{C}$ were illustrated in Fig. 2 . One can see that these textures were the pseudo-confocal conic ones, indicating the columnar liquid crystals for samples $\mathbf{9}$ and $\mathbf{1 0 .}$

Moreover, the XRD analysis was employed to study the columnar stacking behaviors of mesophase of compounds 9 and 10. Their corresponding XRD traces at $70{ }^{\circ} \mathrm{C}$ were exhibited in Fig. 3. In the small-angle region, both samples $\mathbf{9}$ and $\mathbf{1 0}$ showed the three peaks at $4.77^{\circ}, 8.27^{\circ}, 9.55^{\circ}$ and $4.72^{\circ}, 8.18^{\circ}$, $9.45^{\circ}$, respectively. Based on these reflections, the $d$-spacings calculated by formula $d=\lambda /(2 \sin \theta)$ were $18.51 \AA, 10.68 \AA$ and $9.25 \AA$ for compound 9 and $18.70 \AA$ ㅇ, $10.80 \AA$ and $9.35 \AA$ for compound 10, respectively. There data were in agreement with the ratio of $1: 1 / \sqrt{ } 3: 1 / \sqrt{ } 4$ for (100), (110) and (200) reflections of hexagonal columnar mesophase. Also, the lattice parameter $(\alpha)$ for compounds 9 and 10 could be calculated as $21.36 \AA$ and $20.60 \AA$ based on the strong [100] reflections of column phase. In their wide-angle regions, the broad halos at $15-25^{\circ}$ indicated the distances of 3.6-5.9 $\AA$ approximately, which could be
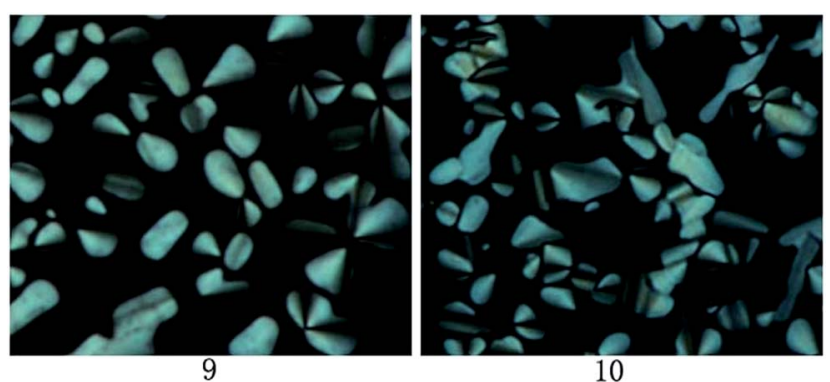

Fig. 2 The textures of compounds 9 and 10 under POM on cooling at $70^{\circ} \mathrm{C}(\times 400)$

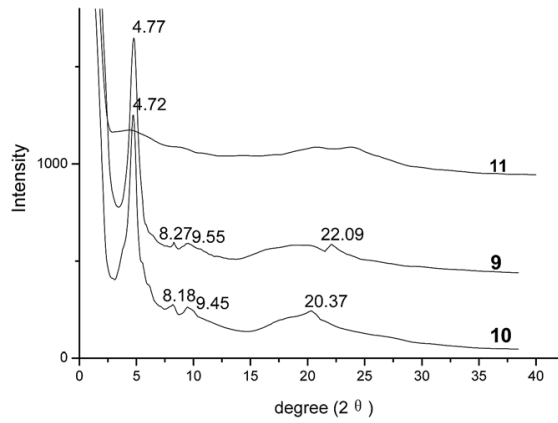

Fig. 3 XRD traces of compounds 9,10 and 11 measured at $70{ }^{\circ} \mathrm{C}$.

attributed to the reflections of very short correlation length of the molten alkyl chains. The weak reflections at $22.09^{\circ}$ for sample 9 and $20.37^{\circ}$ for sample 10, suggesting the spacings of $4.02 \AA$ and $4.36 \AA$, could be assigned for the typical characteristic of $\pi-\pi$ interaction for the intracolumnar distance of columnar liquid crystals. Thus, all these data in small- and wide-angle region implied the hexagonal columnar mesophase for compounds 9 and 10. On the other hand, compound 11 showed no obvious peak, indicating it had been melted at $70{ }^{\circ} \mathrm{C}$ without mesophase, which were in accordance with the analysis of DSC and POM. All these XRD analyses supported that, although one or two diphenylacrylonitrile groups were introduced on the side-chains of triphenylene derivatives 9 and 10, they still maintained the ordered hexagonal columnar mesophase based on the strong columnar-induced mesophase of triphenylene unit as expected.

On the other hand, due to one, two or three AIE active groups of diphenylacrylonitrile grafted onto the triphenylene derivatives 9, 10 and 11, respectively, it was interesting to investigate the influences of the numbers of diphenylacrylonitrile groups on absorption spectra and fluorescence properties. The absorption spectra of compounds $\mathbf{9 , 1 0}$ and $\mathbf{1 1}$ were depicted in Fig. 4. All of them showed very similar absorption profiles with three obvious peaks at $235 \mathrm{~nm}, 277 \mathrm{~nm}$ and $320 \mathrm{~nm}$. But the peaks at $320 \mathrm{~nm}$ exhibited different absorbance. These results were in accordance with their structures. The similar absorption profiles were attributed to their similar functional structures. The different absorbance at $320 \mathrm{~nm}$ were ascribed to the

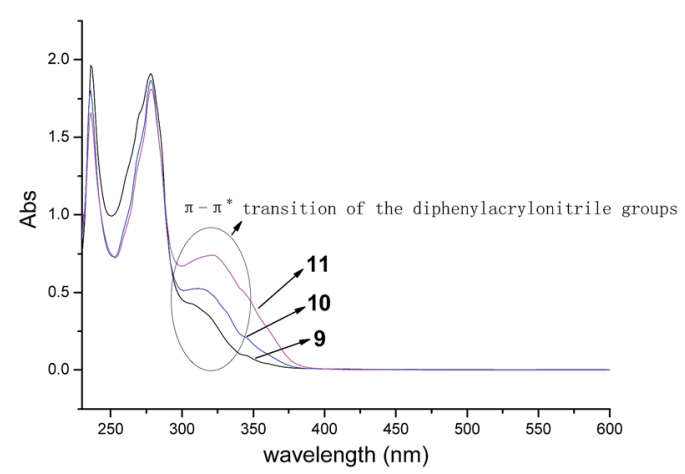

Fig. 4 The UV-vis absorption spectra of samples 9, 10 and 11 in THF solution. 
$\pi-\pi^{*}$ transition of the different numbers of diphenylacrylonitrile groups. The more diphenylacrylonitrile groups resulted in the stronger absorbance at $320 \mathrm{~nm}$.

As diphenylacrylonitrile was a well-known AIE luminogen, the fluorescence (FL) spectra of samples $\mathbf{9 , 1 0}$ and $\mathbf{1 1}$ in THF solution and $\mathrm{THF} / \mathrm{H}_{2} \mathrm{O}$ mixture were measured to investigate the influences of the numbers of diphenylacrylonitrile groups on fluorescence properties. The fluorescence spectra of samples 9, 10 and 11 in $\mathrm{THF} / \mathrm{H}_{2} \mathrm{O}$ mixture with different fractions of $\mathrm{H}_{2} \mathrm{O}$ and their corresponding plot of values $\left(I / I_{0}\right)$ versus the fractions of the aqueous mixtures were exhibited in Fig. 5 . It can be seen that, in pure THF solution, all of them showed weak fluorescence emission. With the addition of $\mathrm{H}_{2} \mathrm{O}$ in THF solution, however, the fluorescence emission increased gradually. The increases of intensity were slow at low water fractions $(<40 \%)$ but became very remarkable afterward. The strongest fluorescence emissions were in the solution of $\mathrm{THF} / \mathrm{H}_{2} \mathrm{O}$ mixtures with $60 \%$ of $\mathrm{H}_{2} \mathrm{O}$ for $\mathbf{1 0}$ and $70 \%$ of $\mathrm{H}_{2} \mathrm{O}$ for 9 and 11. These results certainly suggested that compounds $\mathbf{9 , 1 0}$ and $\mathbf{1 1}$ possessed the AIE fluorescence properties as expected. Due to the low solubility resulting in the precipitation, the fluorescence intensities decreased at high water fractions ( $>60 \%$ for $\mathbf{1 0}$ and $>70 \%$ for $\mathbf{9}$
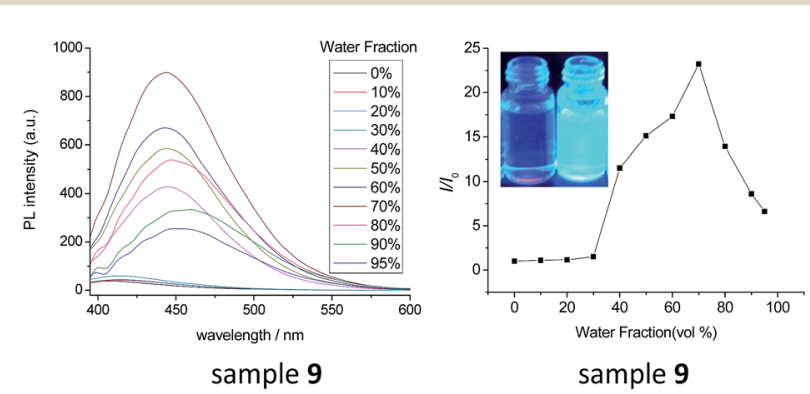

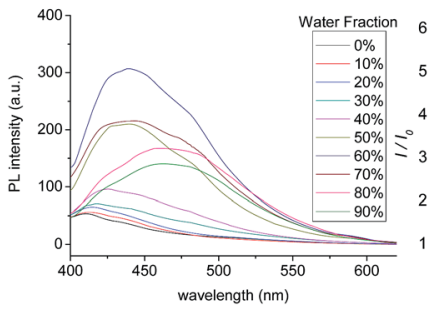

sample 10

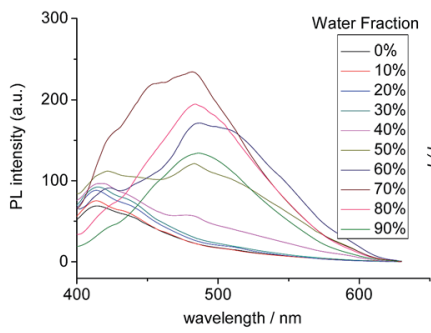

sample 11

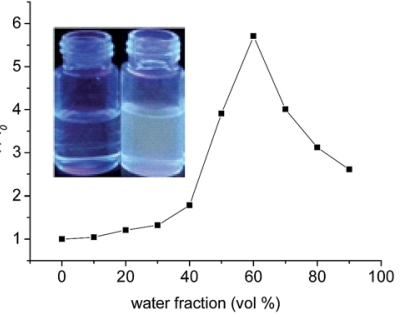

sample 10

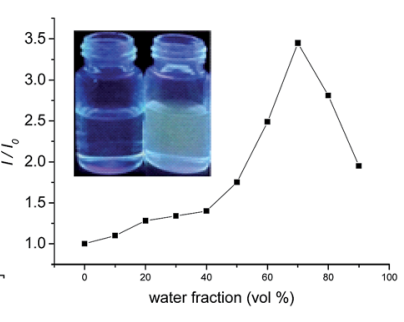

sample 11
Fig. 5 (left) Fluorescence spectra of samples 9, 10 and 11 with different fractions of $\mathrm{H}_{2} \mathrm{O}$ in $\mathrm{THF} / \mathrm{H}_{2} \mathrm{O}$ mixtures $\left(1.0 \times 10^{-5} \mathrm{M}, \lambda_{\text {ex }}=\right.$ $364 \mathrm{~nm})$. (right) Plot of values $\left(/ / I_{0}\right)$ versus the fractions of the aqueous mixtures. $I_{0}=$ emission intensity in pure THF solution. The inset graph was fluorescence pictures of samples in THF solution and 10/90 THF/ $\mathrm{H}_{2} \mathrm{O}$ mixture under UV light. and 11). This other possibility for these phenomena, such as crystalline-induced emission, could be excluded by the XRD analysis which suggested the amorphous state for the precipitation (Fig. S22 †). Moreover, by comparing the fluorescence intensities and $I / I_{0}$ values of samples $\mathbf{9 , 1 0}$ and $\mathbf{1 1}$, it can be seen that the fluorescence intensities in pure THF solution showed the order of $\mathbf{9}<\mathbf{1 0}<\mathbf{1 1}$. But their strongest fluorescence intensities in mixture solutions and their $I / I_{0}$ values presented the inverse order of $\mathbf{9}>\mathbf{1 0}>\mathbf{1 1}$. These phenomena might be explained by their structures. Due to samples $\mathbf{9 , 1 0}$ and $\mathbf{1 1}$ had good solubility and little aggregate in pure THF solution, the more diphenylacrylonitrile groups leaded to the stronger fluorescence intensity, resulted in the order of $\mathbf{9}<\mathbf{1 0}<\mathbf{1 1}$ for the fluorescence intensities of samples $\mathbf{9 , 1 0}$ and $\mathbf{1 1}$ with one, two and three diphenylacrylonitrile groups, respectively. On the other hand, the literatures had revealed that the J-aggregate for diphenylacrylonitrile derivatives increased the fluorescence intensity but the $\mathrm{H}$-aggregate might decrease the fluorescence intensity due to the strong $\pi-\pi^{*}$ interaction. ${ }^{48-51}$ The sample 9 with one diphenylacrylonitrile group preferred to J-aggregate in mixture solutions, enhancing the fluorescence intensity greatly by 24 times. However, due to the two or three diphenylacrylonitrile groups grafted onto the closed $o$-position of one aromatic ring in samples $\mathbf{1 0}$ and 11, the diphenylacrylonitrile groups might be more easily to form the $\mathrm{H}$-aggregate in mixture solutions than sample 9, suggesting that samples $\mathbf{1 0}$ and $\mathbf{1 1}$ might possess not only J-aggregate but also $\mathrm{H}$-aggregate in a certain degree. The existence of some $\mathrm{H}$-aggregate for samples $\mathbf{1 0}$ and 11 decreased fluorescence intensity, although the strong Jaggregate for samples 10 and $\mathbf{1 1}$ still enhanced their fluorescence intensities. The $\mathrm{H}$-aggregate was also confirmed by some blue shift for UV absorption maximum with the increase of water fractions in the solution of $\mathrm{THF} / \mathrm{H}_{2} \mathrm{O}$ mixtures (Fig. S23 $\dagger$ ). Thus, although samples $\mathbf{1 0}$ and $\mathbf{1 1}$ possessed two or three diphenylacrylonitrile groups, their highest fluorescence intensities and maximum $I / I_{0}$ values in mixture solutions were smaller than that of sample $\mathbf{9}$. Moreover, the fluorescence peaks of samples 9, 10 and 11 in mixture solutions exhibited obvious red shifts in comparison with that in pure THF solutions. The values for red shift were $45 \mathrm{~nm}, 51 \mathrm{~nm}$ and $70 \mathrm{~nm}$ for samples $\mathbf{9}$, 10 and 11, respectively. The fluorescence red-shift order of $9<$ $\mathbf{1 0}<\mathbf{1 1}$ might also suggest the existence of some $\mathrm{H}$-aggregates for samples 10 and 11 because the stronger $\pi-\pi^{*}$ interaction of the $\mathrm{H}$-aggregate leaded to the larger red shift than that of Jaggregate. On the other hand, the fluorescence quantum yield $\left(\Phi_{\mathrm{F}}\right)$ of samples $\mathbf{9}, \mathbf{1 0}$ and $\mathbf{1 1}$ in solid state were investigated as $15.9 \%, 7.5 \%$ and $5.6 \%$, respectively. These data revealed that compounds 9, 10 and 11 possessed the middle fluorescence emission in solid state, although some $\mathrm{H}$-aggregate for samples $\mathbf{1 0}$ and $\mathbf{1 1}$ resulting in the order of $\mathbf{9}<\mathbf{1 0}<\mathbf{1 1}$. Combining all these photophysical analysis, it could be summarized that the triphenylene derivatives $\mathbf{9 , 1 0}$ and $\mathbf{1 1}$ with one, two or three diphenylacrylonitrile groups had good AIE fluorescence properties. The largest $I / I_{0}$ values of fluorescence in $T H F / \mathrm{H}_{2} \mathrm{O}$ solution attained 24 times and the highest $\Phi_{\mathrm{F}}$ in solid state achieved $15.9 \%$ for compound 9 . The numbers of diphenylacrylonitrile groups had important influence on the fluorescence properties. 
The multiple diphenylacrylonitrile groups exhibited both the strong AIE fluorescence properties based on the J-aggregate, and weak ACQ effect due to some $\mathrm{H}$-aggregate of multiple diphenylacrylonitrile groups on the closed $o$-position of one aromatic ring. This kind of novel luminescent LC showed both excellent light-emitting property and ordered columnar mesophase, which exhibited potential application as novel fluorescent liquid crystalline functional materials in liquid crystal display and opto-electronic devices, such as novel organic lightemitting diodes and sensors, etc.

\section{Conclusions}

In summary, three novel triphenylene derivatives with one, two or three diphenylacrylonitrile groups on the side chain were designed and synthesized by the Schiff-based condensation in yields of $75-83 \%$. The studies on mesomorphic property revealed that triphenylene derivatives with one or two diphenylacrylonitrile groups exhibited the ordered hexagonal columnar mesophase, but the one with three diphenylacrylonitrile groups showed no mesophase. The photophysical experiments suggested that all of them had good AIE fluorescence properties. The largest fluorescence $I / I_{0}$ values were 24 times and the highest $\Phi_{\mathrm{F}}$ in solid state were $15.9 \%$ for triphenylene derivative with one diphenylacrylonitrile group. The AIE properties presented the order of $\mathbf{9}>\mathbf{1 0}>\mathbf{1 1}$ due to the multiple diphenylacrylonitrile groups exhibited both the strong AIE fluorescence properties and weak ACQ effect. This research confirmed that the columnar AIE liquid crystal could be prepared by using normal discotic coplanar aromatic structure as core and controlling the number of AIE groups on side chain, which is a new strategy to design and synthesis of the novel AIE columnar liquid crystals.

\section{Acknowledgements}

Financial support from the National Natural Science Foundation of China (No. 21406036), Fujian Natural Science Foundation of China (No. 2017J01571), the encouragement and inspiration from Professor Benzhong Tang were greatly acknowledged.

\section{Notes and references}

1 S. Kumar, Chemistry of discotic liquid crystals: from monomers to polymers, CRC press, London, New York, 2010.

2 T. Wöhrle, I. Wurzbach, J. Kirres, A. Kostidou, N. Kapernaum, J. Litterscheidt, J. C. Haenle, P. Staffeld, A. Baro, F. Giesselmann and S. Laschat, Chem. Rev., 2016, 116, 1139-1241.

3 R. J. Bushby and K. Kawata, Liq. Cryst., 2011, 38, 1415-1426. 4 S. Sergeyev, W. Pisula and Y. H. Geerts, Chem. Soc. Rev., 2007, 36, 1902-1929.

5 T. Kato, N. Mizoshita and K. Kishimoto, Angew. Chem., Int. Ed., 2006, 45, 38-68.
6 T. Yasuda, H. Ooi, J. Morita, Y. Akama, K. Minoura, M. Funahashi, T. Shimomura and T. Kato, Adv. Funct. Mater., 2009, 19, 411-419.

7 X. Q. Li, X. Zhang, S. Ghosh and F. Würthner, Chem.-Eur. J., 2008, 14, 8074-8078.

8 M. G. Zhu, H. Y. Guo, F. F. Yang and Z. S. Wang, Liq. Cryst., 2016, 43, 1875-1883.

9 H. Y. Guo, M. G. Zhu, Z. S. Wang and F. F. Yang, Tetrahedron Lett., 2016, 57, 4191-4195.

10 M. G. Zhu, H. Y. Guo, F. F. Yang and Z. S. Wang, RSC Adv., 2017, 7, 4320-4328.

11 N. Mizoshita, T. Tani and S. Inagaki, Adv. Funct. Mater., 2011, 21, 3291-3298.

12 Z. An, J. Yu, S. C. Jones, S. Barlow, S. Yoo, B. Domercq, P. Prins, L. D. A. Siebbeles, B. Kippelen and S. R. Marder, Adv. Mater., 2005, 17, 2580-2581.

13 Z. Chen, U. Baumeister, C. Tschierske and F. Würthner, Chem.-Eur. J., 2007, 13, 450-465.

14 X. T. Fang, H. Y. Guo, J. R. Lin and F. F. Yang, Tetrahedron Lett., 2016, 57, 4939-4943.

15 L. Meng, Q. M. Wu, F. F. Yang and H. Y. Guo, New J. Chem., 2015, 39, 72-76.

16 G. A. Bhavsar and S. K. Asha, Chem.-Eur. J., 2011, 17, 1264612658.

17 M. Bagui, T. Dutta, H. Z. Zhong, S. H. Li, S. Chakraborty, A. Keightley and Z. H. Peng, Tetrahedron, 2012, 68, 28062818.

18 M. G. Zhu, Z. S. Wang, F. F. Yang and H. Y. Guo, Dyes Pigm., 2016, 133, 387-394.

19 S. K. Gupta, S. Setia, S. Sidiq, M. Gupta, S. Kumar and S. K. Pal, RSC Adv., 2013, 3, 12060-12065.

20 X. F. Kong, Z. Q. He, Y. N. Zhang, L. P. Mu, C. J. Liang, B. Chen, X. P. Jing and A. N. Cammidge, Org. Lett., 2011, 13, 764-767.

21 C. L. Chiang, S. M. Tseng, C. T. Chen, C. P. Hsu and C. F. Shu, Adv. Funct. Mater., 2008, 18, 248-257.

22 B. S. Gaylord, S. Wang, A. J. Heeger and G. C. Bazan, J. Am. Chem. Soc., 2001, 123, 6417-6418.

23 Y. Hong, J. W. Y. Lam and B. Z. Tang, Chem. Soc. Rev., 2011, 40, 5361-5388.

24 M. Wang, G. Zhang, D. Zhang, D. Zhu and B. Z. Tang, J. Mater. Chem., 2010, 20, 1858-1867.

25 Y. Hong, J. W. Y. Lam and B. Z. Tang, Chem. Commun., 2009, 28, 4332-4335.

26 J. H. Wan, L. Y. Mao, Y. B. Li, Z. F. Li, H. Y. Qiu, C. Wang and G. Q. Lai, Soft Matter, 2010, 6, 3195-3210.

27 W. Z. Yuan, Z. Q. Yu, P. Lu, C. M. Deng, J. W. Y. Lam, Z. M. Wang, E. Q. Chen, Y. G. Ma and B. Z. Tang, J. Mater. Chem., 2012, 22, 3323-3326.

28 Y. F. Chen, J. S. Lin, W. Z. Yuan, Z. Q. Yu, J. W. Lam and B. Z. Tang, Sci. China: Chem., 2013, 56, 1191-1196.

29 S. L. Yoon, J. H. Kim, K. S. Kim, J. W. Chung, B. Heinrich, F. Mathevet, P. Kim, B. Donnio, A. J. Attias and D. Kim, Adv. Funct. Mater., 2012, 22, 61-69.

30 D. Y. Zhao, F. Fan, J. Cheng, Y. L. Zhang, K. S. Wong, V. G. Chigrinov, H. D. Kwok, L. Guo and B. Z. Tang, Adv. Opt. Mater., 2015, 3, 199-202. 
31 M. M. Stephen, M. Q. Malik and J. G. Damian, Opt. Mater., 2013, 35, 837-842.

32 S. J. Yoon, J. H. Kim, K. S. Kim, J. W. Chung, B. Heinrich, F. Mathevet, P. Kim, B. Donnio and A. J. Attias, Adv. Funct. Mater., 2012, 22, 61-69.

33 W. P. Jin, N. Shusaku, Y. Seong-Jun, D. Tomoki, S. Jangwon, S. Takahiro and Y. P. Soo, Adv. Mater., 2014, 26, 1354-1359.

34 M. Martinez-Abadía, B. Robles-Hernandez, B. Villacampa, M. R. de la Fuente, R. Giménez and M. B. Ros, J. Mater. Chem. C, 2015, 3, 3038-3048.

35 M. Martinez-Abadía, S. Varghese, B. Milian-Medina, J. Gierschner, R. Giménez and M. B. Ros, Phys. Chem. Chem. Phys., 2015, 17, 11715-11724.

36 M. Martinez-Abadía, S. Varghese, R. Giménez and M. B. Ros, J. Mater. Chem. C, 2016, 4, 2886-2893.

37 W. H. Yu, C. Chen, P. Hu, B. Q. Wang, C. Redshaw and K. Q. Zhao, RSC Adv., 2013, 3, 14099-14106.

38 F. F. Yang, H. Y. Guo, J. W. Xie and J. R. Lin, Eur. J. Org. Chem., 2011, 26, 5141-5145.

39 S. Kumar, Liq. Cryst., 2009, 36, 607-638.

40 F. F. Yang, B. T. Xu, H. Y. Guo and J. W. Xie, Tetrahedron Lett., 2012, 53, 1598-1602.
41 A. Zelcer, B. Donnio, C. F. Bourgogne, D. Cukiernik and D. Guillon, Chem. Mater., 2007, 19, 1992-2006.

42 F. F. Yang, J. W. Xie, H. Y. Guo, B. T. Xu and C. C. Li, Liq. Cryst., 2012, 39, 1368-1374.

43 S. Kumar, S. K. Pal, P. S. Kumar and V. Lakshminarayanan, Soft Matter, 2007, 3, 896-900.

44 F. F. Yang, X. Y. Bai, H. Y. Guo and C. C. Li, Tetrahedron Lett., 2013, 54, 409-413.

45 F. F. Yang, Y. M. Zhang, H. Y. Guo and X. Y. Bai, Tetrahedron Lett., 2013, 54, 4953-4956.

46 F. F. Yang, J. Yuan, C. C. Li, H. Y. Guo and X. Y. Yan, Liq. Cryst., 2014, 41, 137-143.

47 C. Imrie and P. Henderson, Chem. Soc. Rev., 2007, 36, 20962124.

48 P. Chen, R. Lu, P. C. Xue, T. H. Xu, G. J. Chen and Y. Y. Zhao, Langmuir, 2009, 25, 8395-8399.

49 S. Y. Li, L. M. He, F. Xiong, Y. Li and G. Q. Yang, J. Phys. Chem. B, 2004, 108, 10887-10892.

50 H. Q. Zhang, S. M. Wang, Y. Q. Li, B. Zhang, C. X. Du, X. J. Wan and Y. S. Chen, Tetrahedron, 2009, 65, 4455-4463.

51 M. Kasha, H. R. Rawls and M. A. El-Bayoumi, Pure Appl. Chem., 1965, 11, 371-392. 